\title{
Overview of essential tremor
}

This article was published in the following Dove Press journal:

Neuropsychiatric Disease and Treatment

6 July 2010

Number of times this article has been viewed

\section{Theresa A Zesiewicz \\ Abinaya Chari \\ Israt Jahan \\ Amber M Miller \\ Kelly L Sullivan}

Department of Neurology, Parkinson Research Foundation, James A. Haley Veterans Administration Hospital, University of South Florida, Tampa, FL, USA
Correspondence:Theresa A Zesiewicz Department of Neurology, University of South Florida, I290I Bruce B Downs Boulevard, Tampa, FL 336/2, USA

Tel 8|3-974-5909

Fax 8|3-974-8032

Email tzesiewi@health.usf.edu

\begin{abstract}
Essential tremor (ET) is one of the most common movement disorders in the world. Despite this, only one medication (propranolol) is approved by the Food and Drug Administration (FDA) to treat it. Fortunately, recent studies have identified some additional medications as treatment of ET. Surgical procedures, such as deep brain stimulation of the ventral intermediate nucleus of the thalamus, offer treatment for refractory tremor. The epidemiology, pathogenesis, and medical and surgical treatment of ET will be discussed in this paper.
\end{abstract}

Keywords: Essential tremor, diagnosis, treatment, pathogenesis

\section{Introduction}

Essential tremor (ET) is one of the most common tremor disorders in the world, and is characterized by a postural and/or kinetic tremor. While the disease is often called "benign", it frequently causes difficulty with everyday tasks such as writing, pouring, and eating. Despite its high prevalence, only one medication (propranolol) is currently approved by the United States Food and Drug Administration (FDA) for its treatment. ${ }^{1}$ The last decade has witnessed advances in ET, including the finding that "nonmotor symptoms", including mood and cognitive dysfunction, appear to occur more commonly in ET patients than in normal controls. ${ }^{2,3}$ Additional medications to primidone and propranolol have been identified that may effectively reduce tremor. This review will focus on the epidemiology, pathogenesis, and current medical and surgical therapy of ET.

\section{Epidemiology}

ET is more prevalent than Parkinson's disease (PD) or Alzheimer disease (AD), and there is no world population that is immune to its development. ${ }^{4}$ The age- and gender-adjusted prevalence of ET is estimated to be 3 to 4 per 1000, with an annual incidence of 23.7 per $100,000 .^{5}$ The incidence of ET rises with increasing age, ${ }^{4}$ although the disease can also affect children. ${ }^{6}$ Approximately $4 \%$ of adults 40 years of age and older are affected by ET. A family history of ET appears to correlate with younger reported age of tremor onset. ${ }^{7}$ While there is no conclusive evidence that ET increases an individual's risk of mortality, one longitudinal prospective study found a small increased risk of death in ET patients. ${ }^{8}$ However, further research is needed to corroborate this finding.

While ET has been thought to have a bimodal age of onset (young adulthood and middle age),${ }^{9}$ one study of ET epidemiology that took place in both a population-based submit your manuscript $\mid$ www.dovepress.com

Dovepress

4795 
practice and tertiary referral center found a bimodal distribution only in the latter. ${ }^{10}$ It is possible that young patients with ET may more likely be referred to a tertiary referral center.

\section{Clinical characteristics of ET}

$\mathrm{ET}$ is considered to be heterogeneous condition with variable clinical expression in affected patients. It is characterized by a postural and/or kinetic tremor in the frequency range of 4 to $12 \mathrm{~Hz}$. Tremor frequency generally decreases over time, while amplitude slowly increases. Alcohol transiently diminishes tremor amplitude in 50\% to $90 \%$ of cases, although this may worsen after the effect of alcohol has worn off.

The location and amplitude of tremor in ET patients varies among patients. Approximately $90 \%$ of patients have tremor in their upper extremities, $30 \%$ have a head tremor, $20 \%$ have a voice tremor, $10 \%$ have a face or jaw tremor, and $10 \%$ of ET patients may have a lower limb tremor. ${ }^{11}$ Isolated head tremor is generally considered part of the clinical spectrum of ET. At least $50 \%$ of ET patients have tandem gait abnormalities. ${ }^{12}$

Recent studies have uncovered the presence on "nonmotor symptoms" including mild cognitive changes, ${ }^{13}$ depression, anxiety, social phobias, olfactory and hearing deficits that occur more frequently in ET patients than in normal agematched controls.

\section{Diagnosis of ET}

ET is a clinical diagnosis, and there are currently no lab tests or radiological scans to aid in the diagnosis. Unfortunately, it is estimated that ET is misdiagnosed in $30 \%$ to $50 \%$ of cases. ${ }^{14,15}$ The consensus statement of the Movement Disorder Society on tremor includes the following clinical criteria for the diagnosis of ET. ${ }^{16}$

\section{Inclusion criteria}

1. Bilateral postural tremor with or without kinetic tremor, involving hands and forearms, that is visible and persistent

2. Duration greater than 5 years

\section{Exclusion criteria}

1. Other abnormal neurological signs (except Froment's sign)

2. Presence of known causes of increased physiological tremor

3. Concurrent or recent exposure to tremorogenic drugs or the presence of a drug withdrawal state
4. Direct or indirect trauma to the nervous system within 3 months before the onset of tremor

5. Historical or clinical evidence of psychogenic origins

6. Convincing evidence of sudden onset or evidence of stepwise deterioration

Deuschl and Elble proposed the following definition of three ET subtypes: ${ }^{17}$

1. Hereditary ET, for patients who fulfill consensus criteria for definite or classic ET and also have a family of at least one affected relative in the immediate family. The onset of tremor in the patient and the family member must occur prior to age 65 years.

2. Sporadic ET, for patients who fulfill the consensus criteria for definite or classic ET, but do not have an immediate family member with ET, and whose age at onset of ET is younger than 65 years.

3. Senile ET, for patients who have definite or classic ET according to consensus criteria, but who develop ET at or after the age of 65 years. Patients may or may not have a family history of ET.

Another set of criteria for the diagnosis of ET may be found in the "The Washington Heights Inwood Genetic Study of Essential Tremor". ${ }^{18}$ These criteria include:

1. On examination, $a+2$ postural tremor* in at least one arm (a head tremor might also be present, but is not sufficient for the diagnosis)

2. On examination, there must be $\mathrm{a}+2$ kinetic tremor during at least four tasks, or a +2 kinetic tremor on one task and $\mathrm{a}+3$ kinetic tremor on a second task. Tasks include pouring water, using a spoon to drink water, drinking water, finger-to-nose maneuver, and drawing spirals

3. If on examination the tremor is present in the dominant hand, then by report it must interfere with at least one activity of daily living (eating, drinking, writing or using the hands). If on examination the tremor is not present in the dominant hand, then this criterion is irrelevant

4. Medications, hyperthyroidism, ethanol, and dystonia are not potential etiological factors

5. Symptoms are not psychogenic (eg, bizarre features, features inconsistent in character, the patient is distractable, or other psychiatric features on examination)

For these criteria, the following scale is used:

0 - No visible tremor

1 - Tremor is of low amplitude, barely perceivable, or intermittent

2 - Tremor is of moderate amplitude $(1-2 \mathrm{~cm})$ and usually present, and is clearly oscillatory 
3 - Tremor is of large amplitude $(>2 \mathrm{~cm})$, violent, and jerky, resulting in difficulty completing the task because of spilling or inability to hold a pen to paper.

Tremor rating scales (TRS) are used to evaluate ET, particularly in clinical trials. A commonly used TRS is the Fahn-Tolosa-Marin rating scale, ${ }^{19}$ which is completed by health care providers. The FTM rating scale evaluates ET based on its appearance, tasks such as drawing lines, spirals, and pouring liquids, and effect on activities or daily living. Elble et al found that a 1-point change in TRS represents a substantial change in tremor amplitude in ET patients. ${ }^{20}$

Gironell et al evaluated the diagnostic potential of neurophysiologic analysis of tremor. ${ }^{21}$ Subjects included three hundred outpatients with postural tremor. Following the first clinic visit, accelerometry and surface electromyography was conducted, and patients were clinically diagnosed by two neurologists who were blinded to the results of neurophysiolgoical testing. Neurophysiologic criteria for the diagnosis of ET required the presence of all of the following:

1. Rhythmic burst of postural tremor on EMG

2. Tremor frequency greater than or equal to $4 \mathrm{~Hz}$

3. Absence of rest tremor or, if present, frequency $1.5 \mathrm{~Hz}$ lower than the postural tremor

4. Absence of tremor latency from rest to postural position

5. Changes of the dominant frequency peak less or equal to $1 \mathrm{~Hz}$ after the weight load test

6. No changes in tremor amplitude after mental concentration.

The neurophysiologic criteria for ET showed a sensitivity of $98 \%$, a specificity of $82 \%$, a positive predictive value of $95 \%$, a negative predictive value of $91 \%$, and positive probability ratio of 5.5 .

\section{Genetics}

ET is commonly inherited by autosomal dominant transmission with incomplete penetrance. In some families, transmission appears to be polygenic. ${ }^{22}$ Identified susceptibility loci for ET include 3q13.1, ${ }^{23} 2 \mathrm{p} 22-\mathrm{p} 25,{ }^{24}$ and $6 \mathrm{p} 23 .{ }^{25}$ Approximately $50 \%$ of ET patients have an affected firstdegree relative, ${ }^{11}$ and first-degree relatives of ET patients also appear to be five times more likely to develop ET than control subjects. ${ }^{26} \mathrm{~A}$ family history of ET appears to correlate with younger reported age of tremor onset. Not all cases of ET have a genetic etiology, however, and the disease may occur sporadically. ${ }^{27}$

\section{Pathogenesis}

The exact pathogenesis of ET is unknown. The disease may be caused by a central oscillator originating in the Guillain Mollaret triangle located in the brainstem. Other areas of the brain that have been implicated in the pathogenesis of ET are the inferior olivary nucleus and the cerebellum. ${ }^{28}$ Evidence for cerebellar involvement includes the presence of "torpedos" or axonal swellings that have been identified in the Purkinje cells in some ET patients. ${ }^{29}$ One study also found a greater loss of Pukinje cells in the cerebellum of ET patients compared to normal controls. ${ }^{30}$

Whether ET is a neurodegenerative disorder or a nondegenerative disease remains controversial. The finding of Lewy body pathology in some ET patients and Purkinje cell loss in others points towards a neurodegenerative process. However, ET may be caused by abnormal oscillatory dysfunction of the motor system, suggesting that it is not a primary neurodegenerative disease, but one in which there may be secondary neuronal damage as the disease progresses. ${ }^{17}$ Increased membrane excitability in motor circuits may play a key role in the pathogenesis of ET. ${ }^{31}$

Several studies suggest that there may be a link between PD and ET, although this remains controversial. For example, one prospective study of patients with ET found a fourfold increase in the risk of developing PD compared to individuals without ET. ${ }^{2}$ Rest tremor, which is commonly found in PD patients, also appears to occur in a subset of ET patients, for reasons that are unknown. Another study compared 53 patients with combined ET and PD to patients with diagnoses of either PD or ET alone, ${ }^{33}$ and found that the gender distribution of patients with a combination of ET and PD (67.9\% male) was identical to that of PD patients (67.9\% male) but different from that of ET patients $(50.0 \%$ male) $(P=0.02)$.

\section{Treatment of ET (pharmacotherapy)}

Pharmacologic treatment of ET should be considered when tremor interferes with activities of daily living. Proper treatment is contingent on a correct diagnosis, and other possible causes of tremor must be excluded. Patients need to be informed that treatment of ET does not cure the disease, but may offer tremor improvement. Medications that are used to treat ET are those that are used to treat other medical conditions, such as hypertension and seizures. It is estimated that medications improve tremor magnitude in ET by about $50 \%$. Unfortunately, $30 \%$ to $50 \%$ of ET patients will not respond to medical therapy. 
First-line pharmacologic agents used to treat ET are propranolol and primidone, although other medications including sotalol, atenolol, alprazolam, and topiramate have also been shown to provide tremor reduction. ${ }^{34}$ In cases of refractory tremor, a reversible, surgical procedure called deep brain stimulation (DBS) into the thalamus may effectively treat tremor.

\section{Antihypertensive medications}

Beta blockers and calcium channel blockers are medications that are commonly used to treat hypertension and other cardiovascular conditions. Propranolol (Inderal) is a nonselective beta-adrenergic receptor antagonist that effectively treats tremor and is the only medication that is FDA-approved for the treatment of ET. The mean dose of propranolol in published, controlled trials was $185.2 \mathrm{mg} /$ day. Propranolol is also available as a long-acting (LA) preparation with once daily dosing. Although this preparation has not been studied as extensively as the immediate formulation, evidence from two clinical studies suggests that it reduces tremor in patients with ET. ${ }^{35,36}$

Other antihypertensive medications, including atenolol (Tenormin) and sotalol (Sotacor) have been shown to reduce ET compared to placebo..$^{37,38}$ One study compared atenolol to other beta blockers (sotalol and propranolol) and found that atenolol had a lower magnitude of effect than either of the other agents. ${ }^{37}$ There is also limited evidence that nadolol (corgard) and nimodipine (nimotop) may treat ET. ${ }^{39,40}$ One study of nadolol compared tremor responders to nonresponders and observed that only patients who previously responded to propranolol experienced significant tremor reduction from nadalol. ${ }^{39}$ Verapamil (Calan) and nifedipine (Adalat) have not been shown to reduce tremor in controlled studies. ${ }^{41}$ Studies of clonidine (Catapress), flunarizine (Sibelium), metoprolol (Lopressor/Toprol), and nicardipine (Cardene) were either limited or produced conflicting results, and their potential use in treating tremor remains uncertain.

\section{Antiepileptics}

Primidone (Mysoline) is an anticonvulsant that effectively treats ET. Studies using accelerometry and clinical rating scales have demonstrated approximately a 50\% reduction in tremor magnitude with the use of primidone, making it a first-line treatment in patients with ET. ${ }^{34}$ Primidone is associated with frequent adverse events including sedation, nausea, vertigo, and an acute toxic reaction which are usually more severe soon after treatment initiation. ${ }^{34}$ A lower initial dose and slower titration has not been shown to reduce adverse effects compared to an initial dose of $25 \mathrm{mg}$ per day and increasing by $25 \mathrm{mg}$ every 4 days. ${ }^{42}$

Gabapentin is an anticonvulsant with a structure similar to gamma-aminobutyric acid (GABA) and is approved as adjunctive therapy for partial seizures. One study found that gabapentin reduce tremor when used as monotherapy in doses of $1,200 \mathrm{mg} /$ day $(\mathrm{n}=16)$, with a $77 \%$ improvement in tremor as measured by accelerometry at day $15 .{ }^{43}$ However, while gabapentin was found to treat ET in a small number of trials as monotherapy, it has not shown efficacy as adjunctive therapy. ${ }^{44,45}$

Topiramate (Topamax) is an anticonvulsant that has been shown to effectively reduce ET. ${ }^{45-48}$ A large randomized, multicenter, double-blinded, placebo-controlled study found that patients treated with topiramate had a $29 \%$ improvement in the FTM rating scale score compared to a $16 \%$ improvement in the placebo-treated patients $(P<0.001) .{ }^{48}$ The average mean dose of topiramate in the study was $292 \mathrm{mg} /$ day, although the between-group difference was significant $(P<0.01)$ at 4 weeks for a topiramate dose of $62 \mathrm{mg} /$ day. Side effects were more common in the topiramate group, and included paresthesia, weight loss, taste abnormalities, memory difficulty, and appetite suppression.

Zonisamide (Zonegran) is an anticonvulsant that may have antitremor efficacy, although study results are mixed. One controlled study found that zonisamide improved ET compared to arotinolol, an antihypertensive agent with mixed alpha and beta-blocking action. ${ }^{50}$ However, at least one additional study failed to find significant antitremor efficacy from zonisamide and a 30\% drop-out rate due to adverse events including fatigue, diarrhea, and headache.

Levetiracetam (Keppra), a pyrrolidine derivative with strong specific binding to cerebellar receptors, failed to show significant tremor reduction when tested for several weeks compared to placebo in several controlled trials. ${ }^{42,51,52}$

Pregabalin (Lyrica): the effect of pregabalin on ET is unclear. One randomized, double-blinded, placebo-controlled trial of 22 patients with ET found a significant reduction in tremor amplitude in patients treated with pregabalin group at a mean dose of $286 \mathrm{mg} /$ day. ${ }^{53}$ However, another controlled trial of $20 \mathrm{ET}$ patients failed to find improvement in tremor rating scale scores in patients taking pregabalin. ${ }^{54}$

\section{Antibiotics}

Isoniazid, an antituberculosis medication, was evaluated in a double-blind, randomized, placebo-controlled study of 
11 patients with ET. ${ }^{55}$ At the end of the 4-week treatment period, only two patients experienced objective or subjective change in their tremor.

\section{Antidepressants}

Antidepressants have not been used to treat ET with much success. One small study failed to find any reduction in clinical ratings of tremor with mirtazapine (Remeron), an antagonist of $\alpha-2$, 5HT2, and 5HT3 receptors. ${ }^{56}$ Trazodone (Desyrel) is a serotoninergic agonist that has been evaluated in two double-blind, randomized, placebo-controlled studies. ${ }^{57,58}$ Both studies failed to find any improvement in tremor evaluations based on clinical rating scales.

\section{Antipsychotics}

Clozapine (Clozaril) is an atypical neuroleptic with minimal extrapyramidal side effects that has been shown to reduce tremor by $45 \%-50 \%$ in two controlled studies. ${ }^{59,60}$ However, clozapine use has a $1 \%$ risk of agranulocytosis, a serious side effect, and its use should be reserved for refractory cases. Weekly white cell counts are required for the first 6 months of therapy and every other week thereafter. Limited evidence is available to determine the utility of olanzapine (Zyprexa) and quetiapine (Seroquel) in reducing tremor.

\section{Antivirals}

Amantadine (Symmetrel) is an antiviral medication that is used to treat PD. A double-blind, cross-over, placebo-controlled trial evaluated amantadine $(200 \mathrm{mg} /$ day $)$ in 16 patients with $\mathrm{ET}^{21}$ After 15 days of treatment tremor measures were not reduced compared to baseline in the amantadine group. Over one-third of patients experienced increased postural tremor.

\section{Barbituates}

Two double-blind, randomized, placebo-controlled crossover studies evaluated the effects of phenobarbital, an anticonvulsant and sedative, on tremor. One study found a significant improvement in accelerometry parameters compared to placebo ${ }^{61}$ but no change in clinical rating scales. The other study failed to find a difference compared to placebo. ${ }^{62}$

\section{Benzodiazepines}

Alprazolam (Xanax) has been shown to reduce clinical ratings of tremor in two double-blind, randomized, controlled studies. ${ }^{63,64}$ Although alprazolam has demonstrated effect in some patients with ET, it should be used cautiously as it has a high potential for abuse. Clonazepam (Klonopin) improved tremor compared to baseline in a blinded, controlled study. ${ }^{65}$ Another study failed to show any improvement in tremor, but had a $60 \%$ dropout rate due to side effects. ${ }^{66}$

\section{Bronchodilators}

Studies of theophylline (Theo-dur), a xanthine derivative bronchodilator on ET, have found conflicting results. One blinded study of a single oral dose of theophylline evaluated changes in tremor over a 24-hour period and found no change as measured by volumetric methods (the volume of water subjects spilled from a cup held in a flexed position for 60 seconds). However, after 3 weeks of treatment with theophylline, tremor was significantly improved using clinical rating scales. ${ }^{67}$ Another blinded study found a reduction in tremor after 4 weeks of treatment compared to placebo. ${ }^{68}$

\section{Carbonic anhydrase inhibitors}

Controlled studies of two carbonic anhydrase inhibitors, acetazolamide (Diamox) and methazolamide (Glauctabs, Neptazane), failed to find a significant difference in tremor evaluations compared to placebo..$^{69,70}$

\section{Treatment considerations for pharmaceutical agents}

Both propranolol and primidone have substantial evidence supporting their effects in reducing symptoms of ET although approximately $30 \%$ of patients will not respond to either of these agents. As initial therapy, primidone and propranolol have shown similar efficacy and the choice of which agent to use primarily depends upon a patient's comorbid conditions and tolerability to either agent. Both medications have shown efficacy for at least 1 year, ${ }^{69,70}$ although there is some evidence for a reduction in tremor control over time with both medications and a dose increase may be necessary.

\section{Botulinum toxin}

Chemodenervation using botulinum toxin A (BTX) has been demonstrated to modestly reduce hand tremor in patients with ET, but its use is hampered by side effects including hand weakness. One randomized, double-blind, placebocontrolled study evaluated the effects of $50 \mathrm{U}$ and $100 \mathrm{U}$ of BTX on limb tremor in 133 patients over a 16-week period..$^{73}$ BTX doses were injected as $15 \mathrm{U}$ into each of the flexor carpi radialis and ulnaris and $10 \mathrm{U}$ into each of the extensor carpi radialis and ulnaris in one group, and $30 \mathrm{U}$ into each of the flexor carpi radialis and ulnaris and $20 \mathrm{U}$ into each of the extensor carpi radialis and ulnaris for the 
second group. Modest benefit was demonstrated by clinical ratings of postural and kinetic tremor 6-weeks postinjection in both groups. Subsequent evaluations 12- and 16-weeks post-injection did not note tremor reduction compared to baseline. Hand weakness was common and occurred in 30\% of patients who received $50 \mathrm{U}$ of BTX and in $70 \%$ of patients that received $100 \mathrm{U}$. One additional controlled study and four uncontrolled studies also demonstrated improvement in limb tremor with BTX.

\section{Surgical treatment}

Surgical procedures may provide treatment of refractory ET. Thalamotomy is a stereotactic procedure that creates a lesion in the ventral intermediate nucleus (VIM) of the thalamus. Studies have typically reported an $80 \%-90 \%$ improvement in tremor symptoms compared to baseline. ${ }^{74-76}$ Side effects of thalamotomy include dysarthria, verbal or cognitive deficits, weakness, confusion, somnolence, and paralysis. These events have been noted to occur in $14 \%-47 \%$ of patients, and usually resolve over time, although hemiparesis and speech difficulties persisted in $16 \%$ of patients in one study. ${ }^{77}$ Due to the risk of adverse events, bilateral thalamotomies are no longer performed to treat ET.

Using placement strategies similar to those used for thalamotomy, DBS uses high frequency electrical stimulation from an implanted electrode to modify activity in the target area, usually the VIM thalamus. The electrodes are connected to a pulse generator which is implanted in the chest wall. The primary advantage of DBS compared to thalamotomy is that simulation parameters such as voltage, pulse frequency, and pulse width can be adjusted to optimize tremor control in the contralateral limbs. These parameters can be adjusted for continued management of tremor. Several studies have evaluated the effect of DBS on ET and have noted a mean improvement in tremor of $60 \%-90 \%$ on clinical ratings. ${ }^{78,79}$

Adverse events have been reported in approximately $18 \%$ of patients in various VIM DBS studies. ${ }^{34}$ These events were usually related to equipment malfunction or lead misplacement. However, other side effects included dysarthria, imbalance, paresthesias, weakness, ischemic changes, and generalized motor seizures. One study reported a death following the procedure due to intracerebral hemorrhage. ${ }^{80}$

Surgical treatment of tremor is usually reserved for patients who are refractory to pharmacotherapy. Thalamotomy and DBS both suppress tremor and the choice of procedure primarily depends upon the patient's circumstances, risk of complications as well as the feasibility of ongoing programming which is required with DBS.

\section{Conclusion}

Despite being one of the most prevalent movement disorders in adults, there are still gaps in the knowledge of pathogenesis and effective treatment of ET. Up to $50 \%$ of patients with ET are misdiagnosed and symptoms of ET can overlap with symptoms of other conditions such as PD. It is important for physicians to understand this disorder and its diagnosis. Many pharmacologic therapies have been tested for effectiveness in treating tremor, but few agents have sufficient data available for their use to be widely recommended and only one agent, propranolol, is indicated for the treatment of ET. Botulinum toxin and surgical interventions are indicated for tremor control but may be associated with more severe or persistent side effects than pharmacologic therapies. Future controlled studies of treatments for ET are warranted.

\section{Disclosure}

The authors report no conflicts of interest in this work.

\section{References}

1. Physicians' Desk Reference. 63rd ed. Montvale, NJ: Thomson PDR; 2009.

2. Benito-Leon J, Louis ED, Bermejo-Pareja F. Population-based casecontrol study of cognitive function in essential tremor. Neurology. 2001;66:69-74.

3. Louis ED, Benito-Leon J, Bermejo-Pareja F. Self-reported depression and anti-depressant medication use in essential tremor: cross-sectional and prospective analyses in a population-based study. Eur J Neurol. 2007;14:1138-1146.

4. Louis ED, Ottman R, Hauser WA. How common is the most common adult movement disorder? estimates of the prevalence of essential tremor throughout the world. Mov Disord. 1998;13(1):5-10.

5. Rajput AH, Offord KP, Beard CM, Kurland LT. Essential tremor in Rochester, Minnesota: a 45-year study. J Neurol Neurosurg Psychiatry. 1984;47:466-470.

6. Louis ED, Dure LS 4th, Pullman S. Essential tremor in childhood: a series of nineteen cases. Mov Disord. 2001;16:921-923.

7. Louis ED, Ottman R. Study of possible factors associated with age of onset in essential tremor. Mov Disord. 2006;21:1980-1986.

8. Louis ED, Benito-León J, Ottman R, Bermejo-Pareja F; Neurological Disorders in Central Spain (NEDICES) Study Group. A population-based study of mortality in essential tremor. Neurology. 2007;69:1982-1989.

9. Brin MF, Koller WC. Epidemiology and genetics of essential tremor. Mov Disord. 1998;(13 Suppl 3):55-63.

10. Louis ED, Ford B, Barnes LF. Clinical subtypes of essential tremor. Arch Neurol. 2000;57:1194-1198.

11. Whaley NR, Putzke JD, Baba Y, et al. Essential tremor: phenotypic expression in a clinical cohort. Parkinsonism Relat Disord. 2007;13:333-339.

12. Singer C, Sanchez-Ramos J, Weiner WJ. Gait abnormality in essential tremor. Mov Disord. 1994;9:193-196.

13. Louis ED. Functional correlates of lower cognitive test scores in essential tremor. Mov Disord. 2010 Jan 27. [Epub ahead of print]

14. Jain S, Lo SE, Louis ED. Common misdiagnosis of a common neurological disorder: how are we misdiagnosing essential tremor? Arch Neurol. 2006 Aug;63:1100-1104. 
15. Schrag A, Munchau A, Bhatia KP, Quinn NP, Marsden CD. Essential tremor: an overdiagnosed condition? J Neurol. 2000;247: 955-959.

16. Deuschl G, Bain P, Brin M, Ad Hoc Scientific Committee. Consensus statement of the Movement Disorder Society on tremor. Mov Disord. 1998;(13 Suppl 3):2-23.

17. Deuschl G, Elble R. Essential tremor - neurodegenerative or nondegenerative disease towards a working definition of ET. Mov Disord. 2009;24:2033-2041.

18. Louis ED, Ottman R, Ford B, Pullman S, Martinez M, Fahn S, Hauser WA. The Washington Heights-Inwood Genetic Study of Essential Tremor: methodologic issues in essential-tremor research. Neuroepidemiology. 1997;16:124-133.

19. Fahn SE, Tolosa E, Marin C. Clinical rating scale for tremor. In: Jankovic J, Tolosa E, editors. Parkinson's Disease and Movement Disorders, 2nd ed. Baltimore, MA: Williams and Wilkins; 1988:225-234.

20. Elble RJ, Pullman SL, Matsumoto JY, Raethjen J, Deuschl G, Tintner R; Tremor Research Group. Tremor amplitude is logarithmically related to 4- and 5-point tremor rating scales. Brain. 2006;129 (Pt 10):2660-2666.

21. Gironell A, Kulisevsky J, Pascual-Sedano B, Flamarich D. Effect of amantadine in essential tremor: a randomized, placebo-controlled trial. Mov Disord. 2006;21:441-445.

22. Deng H, Le W, Jankovic J: Genetics of essential tremor. Brain. 2007, 130:1456-1464.

23. Gulcher JR, Jonsson P, Kong A, Kristjansson K, Frigge ML, Karason A, et al. Mapping of a familial essential tremor gene, FET1, to chromosome 3q13. Nat Genet. 1997;17:84-87.

24. Higgins JJ, Pho LT, Nee LE. A gene (ETM) for essential tremor maps to chromosome 2p22-p25. Mov Disord 1997;12:859-864.

25. Shatunov A, Sambuughin N, Jankovic J, Elble R, Lee HS, Singleton AB, et al. Genomewide scans in North American families reveal genetic linkage of essential tremor to a region on chromosome $6 \mathrm{p} 23$. Brain. 2006;129:2318-2331.

26. Louis ED, Ford B, Frucht S, Barnes LF, Tang MX, Ottman R. Risk of tremor and impairment from tremor in relatives of patients with essential tremor: a community-based family study. Ann Neurol. 2001;49:761-769.

27. Louis ED. Etiology of essential tremor: should we be searching for environmental causes? Mov Disord. 2001;16:822-829.

28. Elble RJ. Animal models of action tremor. Mov Disord. 1998;13 Suppl 3:35-39.

29. Louis ED, Faust PL, Vonsattel JP, et al. Torpedoes in Parkinson's disease, Alzheimer's disease, essential tremor, and control brains. Mov Disord. 2009;24:1600-1605.

30. Louis ED, Faust PL, Vonsattel JP, et al. Neuropathological changes in essential tremor: 33 cases compared with 21 controls. Brain. 2007;130(Pt 12):3297-3307.

31. Shaikh AG, Kiura K, Optican LM, Ramat S, Tripp RM, Zee DS. Hypothetical membrane mechanisms in essential tremor. JTransl Med. 2008;6(1):68.

32. Benito-León J, Louis ED, Bermejo-Pareja F; Neurological Disorders in Central Spain Study Group. Risk of incident Parkinson's disease and parkinsonism in essential tremor: a population based study. J Neurol Neurosurg Psychiatry. 2009;80:423-425.

33. Minen MT, Louis ED. Emergence of Parkinson's disease in essential tremor: a study of the clinical correlates in 53 patients. Mov Disord. 2008;23:1602-1605.

34. Zesiewcz TA, Elble R, Louis ED, et al. Practice parameter: Therapies for essential tremor. Report of the Quality Standards Subcommittee of the American Academy of Neurology. Neurology. 2005;64: 2008-2020.

35. Cleeves L, Findley LJ. Propranolol and propranolol-LA in essential tremor: a double blind comparative study. J Neurol Neurosurg Psychiatry. 1988;51:379-384.

36. Koller WC. Long-acting propranolol in essential tremor. Neurology. 1985;35:108-110.
37. Jefferson D, Jenner P, Marsden CD. Beta-Adrenoreceptor antagonists in essential tremor. J Neurol Neurosurg Psychiatry. 1979;42:904-909.

38. Leigh PN, Jefferson D, Twomey A, et al. Beta-adrenoreceptor mechanisms in essential tremor; a double-blind placebo controlled trial of metoprolol, sotalol and atenolol. J Neurol Neurosurg Psychiatry. 1983;46:710-715.

39. Koller WC. Nadolol in essential tremor. Neurology. 1983;33:1076-1077.

40. Biary N, Bahou Y, Sofi MA, et al. The effect of nimodipine on essential tremor. Neurology. 1995;45:1523-1525.

41. Topaktas S, Onur R, Dalkara T. Calcium channel blockers and essential tremor. Eur Neurol. 1987;27:114-119.

42. O'Suilleabhain P, Dewey RB. Randomized trial comparing primidone initiation schedules for treating essential tremor. Mov Disord. 2002; 17:383-386.

43. Gironell A, Kulisevsky J, Barbonoj M, et al. A randomized placebocontrolled comparative trial of gabapentin and propranolol in essential tremor. Arch Neurol. 1999;56:475-480.

44. Ondo W, Hunter C, Vuong KD, et al. Gabapentin for essential tremor: a multiple-dose, double-blind, placebo-controlled trial. Mov Disord. 2000;15:678-682.

45. Pahwa R, Lyons K, Hubble JP, et al. Double-blind, controlled trial of gabapentin in essential tremor. Mov Disord. 1998;13:465-467.

46. Galvez-Jimenez N, Hargreave M. Topiramate and essential tremor. Ann Neurol. 2000;47:837-838.

47. Connor GS. A double-blind placebo-controlled trial of topiramate treatment for essential tremor. Neurology. 2002;59:132-134.

48. Ondo WG, Jankovic J, Connor GS, et al; Topiramate Essential Tremor Study Investigators. Topiramate in essential tremor: a double-blind, placebo-controlled trial. Neurology. 2006;66:672-677.

49. Connor GS, Edwards K, Tarsy D. Topiramate in essential tremor: findings from double-blind, placebo-controlled, crossover trials. Clin Neuropharmacol. 2008;31:97-103.

50. Morita S, Miwa H, Kondo T. Effect of zonisamide on essential tremor: a pilot crossover study in comparison with arotinolol. Parkinsonism Relat Disord. 2005;11:101-103.

51. Bushara KO, Malik T, Exconde RE. The effect of levetiracetam on essential tremor. Neurology. 2005;64:1078-1080.

52. Sullivan KL, Hauser RA, Zesiewicz TA. Levetiracetam for the treatment of essential tremor. Mov Disord. 2005;20:640.

53. Zesiewicz TA, Ward CL, Hauser RA, et al. A pilot, double-blind, placebo-controlled trial of pregabalin (Lyrica) in the treatment of essential tremor. Mov Disord. 2007;22:1660-1663.

54. Ferrara JM, Kenney C, Davidson AL, Shinawi L, Kissel AM, Jankovic J. Efficacy and tolerability of pregabalin in essential tremor: a randomized, double-blind, placebo-controlled, crossover trial. J Neurol Sci. 2009;285(1-2):195-197.

55. Hallett M, Ravits J, Dubinsky RM, et al. A double-blind trial of isoniazid for essential tremor and other action tremors. Mov Disord. $1991 ; 6: 253-256$.

56. Pahwa R, Lyons KE. Mirtazapine in essential tremor: a double-blind, placebo-controlled pilot study. Mov Disord. 2004;18:584-587.

57. Koller WC. Tradozone in essential tremor. Clin Neuropharmacol. 1989;12:134-137.

58. Cleeves J, Findley LJ. Trazodone is ineffective in essential tremor. J Neurol Neurosurg Psychiatry. 1990;53:268-269.

59. Ceravolo R, Salvetti S, Piccini P, et al. Acute and chronic effects of clozapine in essential tremor. Mov Disord. 1999;14:468-472.

60. Pakkenberg H, Pakkenberg B. Clozapine in the treatment of tremor. Acta Neurol Scand. 1986;73:295-297.

61. Baruzzi A, Procaccianti G, Martinelli P, et al. Phenobarbital and propranolol in essential tremor: a double-blind controlled clinical trial. Neurology. 1983;33:296-300.

62. Sasso E, Perucca E, Calzetti S. Double-blind comparison of primidone and phenobarbital in essential tremor. Neurology. 1988;38:808-810.

63. Gunal DI, Afsar N, Bekiroglu N, et al. New alternative agents in essential tremor therapy: double-blind placebo-controlled study of alprazolam and acetazolamide. Neurol Sci. 2000;21:315-317. 
64. Huber SJ, Paulson GW. Efficacy of alprazolam for essential tremor. Neurology. 1988;38:241-243.

65. Biary N, Koller W. Kinetic predominant essential tremor: successful treatment with clonazepam. Neurology. 1987;37:471-474.

66. Thompson C, Lang A, Parkes JD, et al. A double-blind trial of clonazepam in benign essential tremor. Clin Neuropharmacol. 1984;7:83-88.

67. Mally J, Stone TW. The effect of theophylline on essential tremor: the possible role of GABA. Pharmacol Biochem Behav. 1991;39:345-349.

68. Mally J, Stone TW. Efficacy of an adenosine antagonist, theophylline, in essential tremor: comparison with placebo and propranolol. J Neurol Sci. 1995;132:129-132.

69. Busenbark K, Parwa R, Hubble J, et al. The effect of acetazolamide on essential tremor: an open-label trial. Neurology. 1992;42:1394-1395.

70. Busenbark K, Pahwa R, Hubble J, et al. Double-blind controlled study of methazolamide in the treatment of essential tremor. Neurology. 1993;43:1045-1047.

71. Sasso E, Perucca E, Fava R, et al. Primidone in the long-term treatment of essential tremor: a prospective study with computerized quantitative analysis. Clin Neuropharmacol. 1990;13:67-76.

72. Calzetti S, Sasso E, Baratti M, et al. Clinical and computer-based assessment of long-term therapeutic efficacy of propranolol in essential tremor. Acta Neurol Scand. 1990;81:392-396.
73. Brin MF, Lyons KE, Doucette J, et al. A randomized, double masked, controlled trial of botulinum toxin type A in essential hand tremor. Neurology. 2001;56:1523-1528.

74. Schuurman PR, Bosch DA, Bossuyt PM, et al. A comparison of continuous thalamic stimulation and thalamotomy for suppression of severe tremor. $N$ Engl J Med. 2000;342:461-468.

75. Nagaseki Y, Shibazaki T, Hirai T, et al. Long-term follow-up results of selective VIM-thalamotomy. J Neurosurg. 1986;65:296-302.

76. Zirh A, Reich SG, Dougherty PM, et al. Stereotactic thalamotomy in the treatment of essential tremor of the upper extremity: reassessment including a blinded measure of outcome. J Neurol Neurosurg Psychiatry. 1999;66:772-775.

77. Akbostanci MC, Slavin KV, Burchiel KJ. Stereotactic ventral intermedial thalamotomy for the treatment of essential tremor: results of a series of 37 patients. Stereotact Funct Neurosurg. 1999;72:174-177.

78. Pahwa R, Lyons KL, Wilkinson SB, et al. Bilateral thalamic stimulation for the treatment of essential tremor. Neurology. 1999;53:1447-1450.

79. Carpenter MA, Pahwa R, Miyawaki KL, et al. Reduction in voice tremor under thalamic stimulation. Neurology. 1998;50:796-798.

80. Schuurman PR, Bosch DA, Bossuyt PM, et al. A comparison of continuous thalamic stimulation and thalamotomy for suppression of severe tremor. N Engl J Med. 2000;342:461-468.
Neuropsychiatric Disease and Treatment

\section{Publish your work in this journal}

Neuropsychiatric Disease and Treatment is an international, peerreviewed journal of clinical therapeutics and pharmacology focusing on concise rapid reporting of clinical or pre-clinical studies on a range of neuropsychiatric and neurological disorders. This journal is indexed on PubMed Central, the 'PsycINFO' database and CAS, and is the official

\section{Dovepress}

journal of The International Neuropsychiatric Association (INA). The manuscript management system is completely online and includes a very quick and fair peer-review system, which is all easy to use. Visit http://www.dovepress.com/testimonials.php to read real quotes from published authors. 